\title{
Response of hydrothermal system to stress transients at Lassen Volcanic Center, California, inferred from seismic interferometry with ambient noise
}

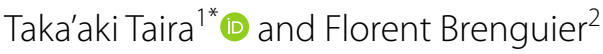

\begin{abstract}
:
Time-lapse monitoring of seismic velocity at volcanic areas can provide unique insight into the property of hydrothermal and magmatic fluids and their temporal variability. We established a quasi real-time velocity monitoring system by using seismic interferometry with ambient noise to explore the temporal evolution of velocity in the Lassen Volcanic Center, Northern California. Our monitoring system finds temporal variability of seismic velocity in response to stress changes imparted by an earthquake and by seasonal environmental changes. Dynamic stress changes from a magnitude 5.7 local earthquake induced a $0.1 \%$ velocity reduction at a depth of about $1 \mathrm{~km}$. The seismic velocity susceptibility defined as ratio of seismic velocity change to dynamic stress change is estimated to be about $0.006 \mathrm{MPa}^{-1}$, which suggests the Lassen hydrothermal system is marked by high-pressurized hydrothermal fluid. By combining geodetic measurements, our observation shows that the long-term seismic velocity fluctuation closely tracks snowinduced vertical deformation without time delay, which is most consistent with an hydrological load model (either elastic or poroelastic response) in which surface loading drives hydrothermal fluid diffusion that leads to an increase of opening of cracks and subsequently reductions of seismic velocity. We infer that heated-hydrothermal fluid in a vapor-dominated zone at a depth of 2-4 km range is responsible for the long-term variation in seismic velocity

Keywords: Lassen Volcanic Center, Ambient seismic noise, Seismic interferometry, Monitoring seismic velocity change, Dynamic stress change, Seismic velocity susceptibility, Hydrothermal system, Seasonal variation, Hydrological loading
\end{abstract}

\section{Introduction}

The Lassen Volcanic Center (LVC) is one of the southernmost active volcanoes in the Cascades Volcanic Arc and has experienced at least 14 eruptions in the last 100,000 years (Clynne and Muffler 2010). A series of eruptions occurred in 1914-1917 including steam explosions and column-collapse pyroclastic flows (Clynne and Muffler 2010; Clynne et al. 2012). The US Geological Survey (USGS) designates the LVC as "very high threat volcano" (Ewert et al. 2006) and has been monitoring

\footnotetext{
*Correspondence: taira@berkeley.edu

1 Berkeley Seismological Laboratory, University of California, Berkeley, CA 94720, USA

Full list of author information is available at the end of the article
}

tectonic and volcanic seismicity by an array of seismometers (Moran 2004). Crustal extension in the Basin and Range Province causes normal-faulting earthquakes in and around the LVC, including the 1946 M 5.0 and 1950 M 5.5 earthquakes (Norris et al. 1997). The majority of volcanic seismicity consists of clusters of earthquakes (or earthquake swarms) occurring over several days (Klein 1979). These seismic activities were likely linked to fluid pressure fluctuations from the Lassen hydrothermal system (Janik and McLaren 2010; Ingebritsen et al. 2015).

The Lassen hydrothermal system is the most extensive active hydrothermal system of the Cascade arc and is characterized by a shallow vapor-dominated reservoir underlain by $\sim 240{ }^{\circ} \mathrm{C}$ hot waters (Muffler et al. 1982; Ingebritsen and Sorey 1985; Ingebritsen et al. 2016). This 
hydrothermal system has been suggested to be driven by heat from cooling mafic magma reservoirs beneath the LVC (Clynne et al. 2012). A number of long-period earthquakes (depth of $15-20 \mathrm{~km}$ ) were detected in the LVC (Pitt et al. 2002), which might represent movements of magma at depth. The extensively active Lassen hydrothermal system may pose potential hazards to the Lassen region including emissions of gases and hydrothermal explosions.

There is thus a need of continuous monitoring of the hydrothermal system. In the last several years, seismic interferometry has become one of the most effective seismological tools for time-lapse monitoring of hydrothermal and magmatic reservoirs (e.g., Brenguier et al. 2008b, 2011, 2016; Haney et al. 2009; Nagaoka et al. 2010; Jaxybulatov et al. 2014; Caudron et al. 2015; Spica et al. 2015). Here, we apply seismic interferometry to continuous seismic recordings for investigating the temporal seismic behavior of the Lassen hydrothermal system.

\section{Data and analysis}

To establish an automated seismic velocity monitoring system for the LVC, we have analyzed continuous seismic records from the six seismic stations of the Northern California Seismic Network (NCSS) that surround the Lassen Peak (Fig. 1). One of six stations, LDH is equipped with a three-component broadband sensor (CMG3ESPC) with a flat response from $60 \mathrm{~s}$ to $50 \mathrm{~Hz}$. The remaining five stations are equipped with a short-period L4 vertical geophone sensor with a natural frequency of $1 \mathrm{~Hz}$. All stations have been maintained by USGS.

We computed noise cross-correlation functions (NCFs) for continuous seismic recordings archived at the Northern California Earthquake Data Center (NCEDC 2014) by using MSNoise software (Lecocq et al. 2014). Our monitoring system has been focused on analyzing the seismic data after a major change of the USGS recording system that occurred in late 2011 (NCEDC 2014). The seismic recordings before this 2011 upgrade were collected with different sampling rate and equipment. We excluded the pre-2012 data for our analysis to avoid any possible artificial velocity changes due to equipment changes, although correcting the full instrument response will minimize such artificial variations in velocity.

NCFs were obtained by a slightly modified version of the data processing described in Brenguier et al. (2008a) and Taira et al. (2015). We first removed the instrument response from 1-day-long waveform to obtain ground motion in displacement. Daily displacement data were bandpassed between 0.08 and $2.0 \mathrm{~Hz}$, down-sampled into $10 \mathrm{~Hz}$, and split into 30-min-long data. Those 30-minlong data were spectral whitened in a frequency range of $0.1-0.9 \mathrm{~Hz}$ and then one-bit normalized. With those

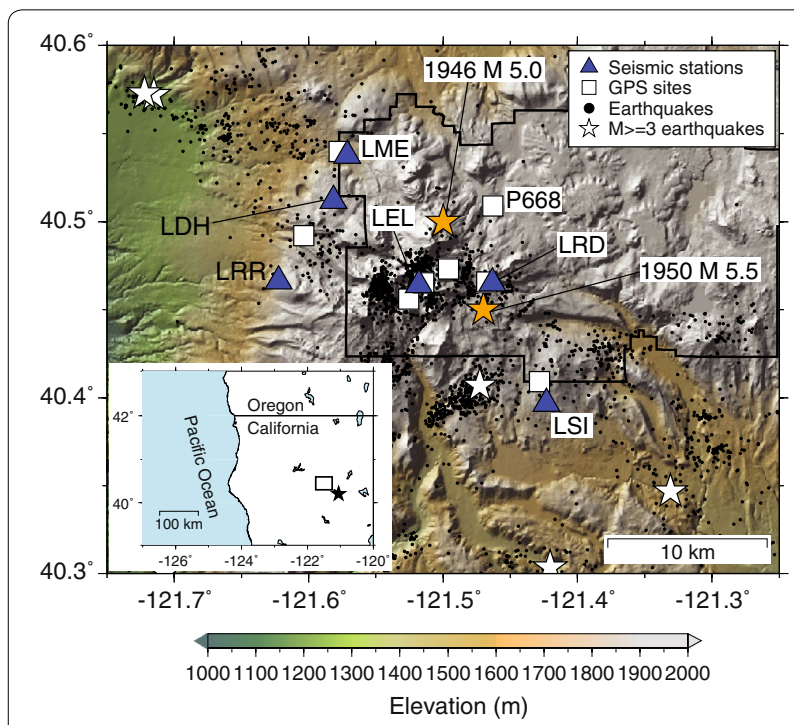

Fig. 1 Map view of the Lassen Volcanic Center. The blue triangles and white squares show the locations of seismic stations and Global Positioning System (GPS) sites, respectively. Also shown are the background earthquakes (black dots) during January 1984 through June 2016. The locations were determined by a double-difference relocation approach (Waldhauser and Schaff 2008; Waldhauser 2009) and were extracted from NCEDC (NCEDC 2014). White stars represent locations of the $M \geq 3$ earthquakes. Orange stars are two $M \geq 5$ Lassen earthquakes from the Berkeley Digital Seismic Network earthquake catalog. The solid line indicates the boundary of the Lassen Volcanic National Park. The inset figure shows our target area shown in the solid rectangle. Also shown in this inset figure is the location of the 2013 M 5.7 Greenville earthquake (solid star) that locates $\sim 50 \mathrm{~km}$ southeast of station LEL

one-bit normalized data, the NCFs were computed for all possible combinations of components. Daily NCFs were then obtained by stacking 30-min NCFs.

We employed the moving-window cross-spectral technique (Clarke et al. 2011) to obtain temporal variability of seismic velocity $(\mathrm{d} v / v)$, by measuring time delay $(\mathrm{d} t)$ between the 5-day stack of NCFs and reference NCFs (Brenguier et al. 2008b; Wegler et al. 2009) with an assumption of a constant velocity change around the stations. The reference NCF was computed by averaging over daily NCFs obtained from January 2012 through June 2016 (Fig. 2). Coda parts of NCFs in which scattered surface wave arrived were used to measure $\mathrm{d} t$ to minimize effects of the time-dependent distributions of ambient noise sources (e.g., Stehly et al. 2008; Hadziioannou et al. 2011). The coda parts were defined from -50 to $-20 \mathrm{~s}$ and 20 to $50 \mathrm{~s}$ to avoid direct surface waves for our $\mathrm{d} t$ measurements (Fig. 2). We also expect that this coda window will minimize the contribution of scattered body waves. Obermann et al. (2013a) showed with numerical experiments that the body wave contribution will be 

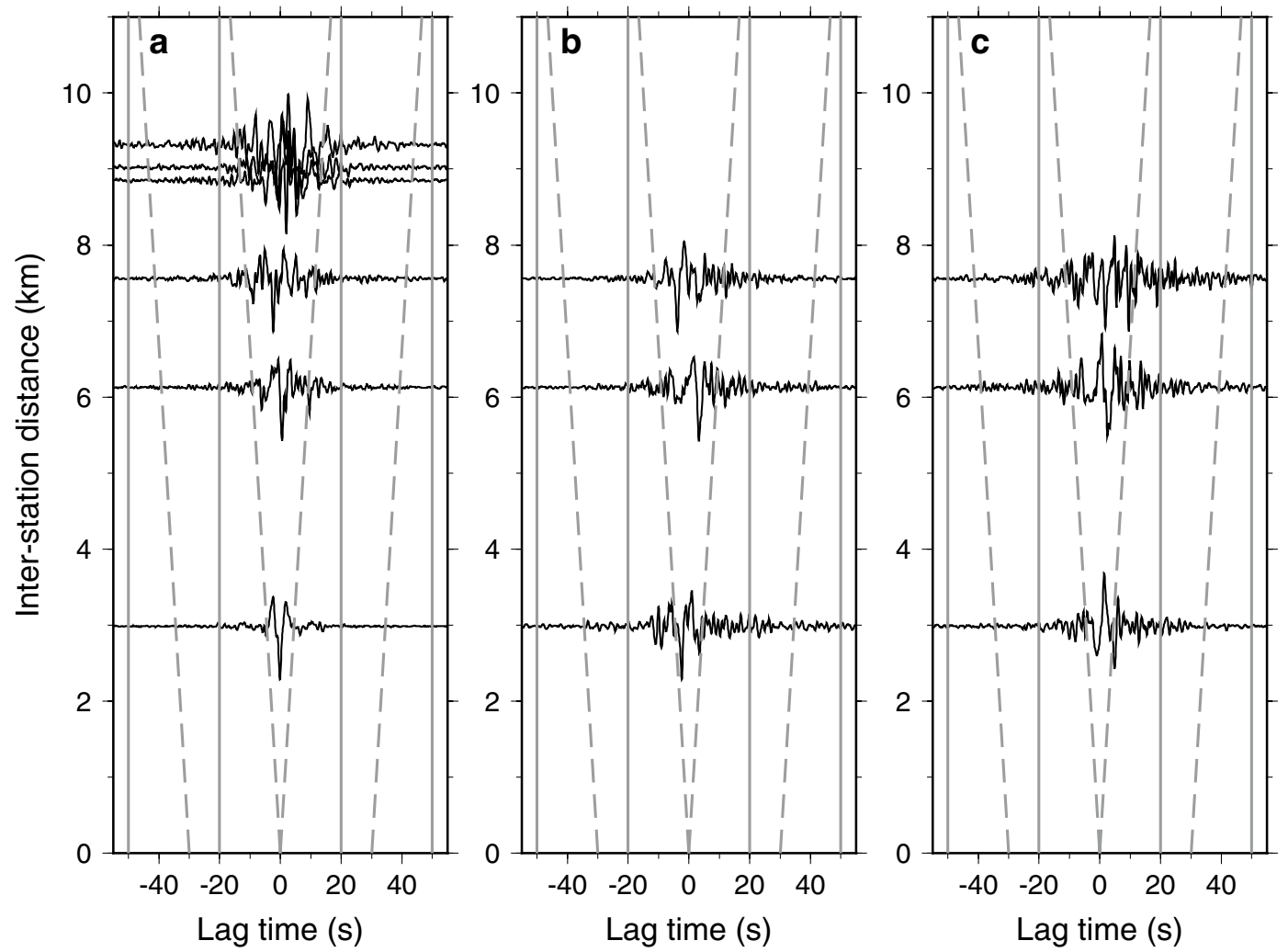

Fig. 2 Reference NCFs for a vertical-vertical, b vertical-radial, and c vertical-transverse components in a frequency of $0.1-0.9 \mathrm{~Hz}$ as a function of inter-station distances. The amplitudes are normalized by their maximum amplitudes. Gray lines indicate the coda window ranging from -50 to $-20 \mathrm{~s}$ and 20 to $50 \mathrm{~s}$. Dashed gray lines show another coda window based on the inter-station distance (see text details in "Results" section)

dominant after six times the normalized transport mean free time $t^{*}=l / c$ where $l$ is the transport mean free path and $c$ is the surface wave velocity. As mentioned in Obermann et al. (2013a), the estimation of the transport mean free path is often difficult. However, if we use $l=50 \mathrm{~km}$ that was used in Obermann et al. (2013b) for Piton de la Fournaise volcano together with $c=2.0-3.0 \mathrm{kms}^{-1}$, the body wave contribution would be significant after 100$150 \mathrm{~s}$ that is outside our coda window.

In coda windows defined, $\mathrm{d} t$ was computed with a sliding time window of $10 \mathrm{~s}$ shifted by $1 \mathrm{~s}$. The resultant $\mathrm{d} t$ measurements were used to infer $\mathrm{d} v / v$ when the value of cross-correlation between the 5-day stack and reference NCFs exceeds 0.85 for each sliding window. We confirmed that NCFs from all pairs of stations have good signal-to-noise ratio throughout the coda window and provide high values of cross-correlation $(>0.80)$ for the $\mathrm{d} t$ measurements. However, through our noise crosscorrelation analysis, we find large time gaps over several months during winter season for station LRD and excluded the pairs of stations including station LRD. Our analysis also finds possible clock drift in the recording system for station LSI. Although this clock drift can be corrected (Stehly et al. 2007; Sens-Schönfelder 2008), this station was excluded for $\mathrm{d} v / v$ measurements. After these data-quality controls, the total number of the seismic station is four and consisted of one three-component sensor, LDH and three short-period vertical sensors, LEL, LME, and LRR. Most of those four stations were located in the west side of the LVC (Fig. 1). As one three-component site (LDH) was only available for our analysis, $\mathrm{d} t$ (and $\mathrm{d} v / v)$ measurements were limited to use vertical-vertical (ZZ), vertical-radial (ZR), vertical-transverse (ZT), radial-vertical (RZ), and transverse-vertical (TZ) components of NCFs (Fig. 2). Note that RZ and TZ components are recorded in acausal parts (lapse time $<0$ ) of ZR and ZT components, respectively. We obtained 12 individual channel pairs of NCFs from the four stations. To explore temporal variability in $\mathrm{d} v / v$, we stacked $\mathrm{d} t$ measurements from the 12 channel pairs and obtained $\mathrm{d} v / v$ with an assumption of a homogeneous velocity change, $\mathrm{d} v / v=-\mathrm{d} t / t$ (Brenguier et al. 2008b; Wegler et al. 2009).

\section{Results}

Our seismic velocity monitoring system has been updating the time history of $d v / v$ every day when the NCEDC 
archives the previous day's continuous seismic recordings. The most updated $\mathrm{d} v / v$ time series can be found at http://earthquakes.berkeley.edu/ taira/LP/LP_Noise. html (last accessed on September 15, 2016). In this paper, we show the temporal evolution of $\mathrm{d} v / v$ from January 2012 through June 2016 (Fig. 3). The most notable feature of the $\mathrm{d} v / v$ time series shown in Fig. $3 \mathrm{a}$ is a sudden velocity drop (about $0.1 \%$ ) occurring in late May 2013. We searched for local and teleseismic earthquakes that might be linked to this velocity reduction. The magnitude $(M)$ 5.7 Greenville earthquake occurred on May 24, 2013, and its epicenter is located about $50 \mathrm{~km}$ away from the LVC (the inset figure in Fig. 1). The timing of the occurrence of this Greenville earthquake appears to be directly correlated with the onset of the velocity reduction (Fig. 3b). After this velocity reduction, the $\mathrm{d} v / v$ gradually increased over time. However, there seems to be a long-term velocity perturbation that might be superimposed on the velocity recovery.

To explore the underlying mechanism of seismic velocity changes observed, we evaluated the depth extent of changes in velocity by examining the frequency dependence of $\mathrm{d} v / v$ (e.g., Wu et al. 2016). We recomputed NCFs with three different frequency bands $(0.1-0.5 \mathrm{~Hz}, 0.3-$ $0.7 \mathrm{~Hz}$, and $0.5-0.9 \mathrm{~Hz}$ ) that were used for the spectral whitening process and obtained the frequency-dependent $\mathrm{d} v / v$ time series (Fig. 4). We find that the $\mathrm{d} v / v$ time series in the $0.5-$ to $0.9-\mathrm{Hz}$ band most clearly shows the velocity reduction and the subsequent velocity recovery (Fig. 4a). On the contrary, the velocity reduction was not clearly registered for lower frequency bands $(0.3-0.7 \mathrm{~Hz}$ and $0.1-0.5 \mathrm{~Hz})$. In those frequency bands, long-term variations seem to be observed (Fig. 4b, c). Note, however, that $\mathrm{d} v / v$ measurements on a 5 -day stack are not stable in the $0.1-$ to $0.5-\mathrm{Hz}$ band. To further explore longterm velocity fluctuations, we computed $\mathrm{d} v / v$ for stack of 30 days for individual frequency bands (red lines in Fig. 4). The amplitude of the long-term variation is about $\pm 0.03 \%$ in the 0.3 - to $0.7-\mathrm{Hz}$ band. A seasonal variation is seen in the $0.1-$ to $0.5-\mathrm{Hz}$ band in which $\mathrm{d} v / v$ gradually decreased in the winter season (Fig. 4c). Although we used coda of NCFs to explore $\mathrm{d} v / v$, this seasonal velocity variation might be related to seasonal variability in distribution of noise source.

We also tested another coda window in which we define the starting time based on inter-station distances and surface wave velocity (dashed gray lines in Fig. 2). We assume that the velocity of surface wave (both direct Rayleigh and Love waves) is $2.0 \mathrm{kms}^{-1}$ in a frequency band of $0.1-0.9 \mathrm{~Hz}$ and defined that the coda part starts at three times the arrival time of the direct surface wave. The length of the coda part was fixed to be $30 \mathrm{~s}$ for all pairs of stations. The resultant temporal evolutions of $d v / v$ in Fig. 5 are comparable to those shown in Fig. 4, which would confirm that our findings do not dependent on coda windows used.

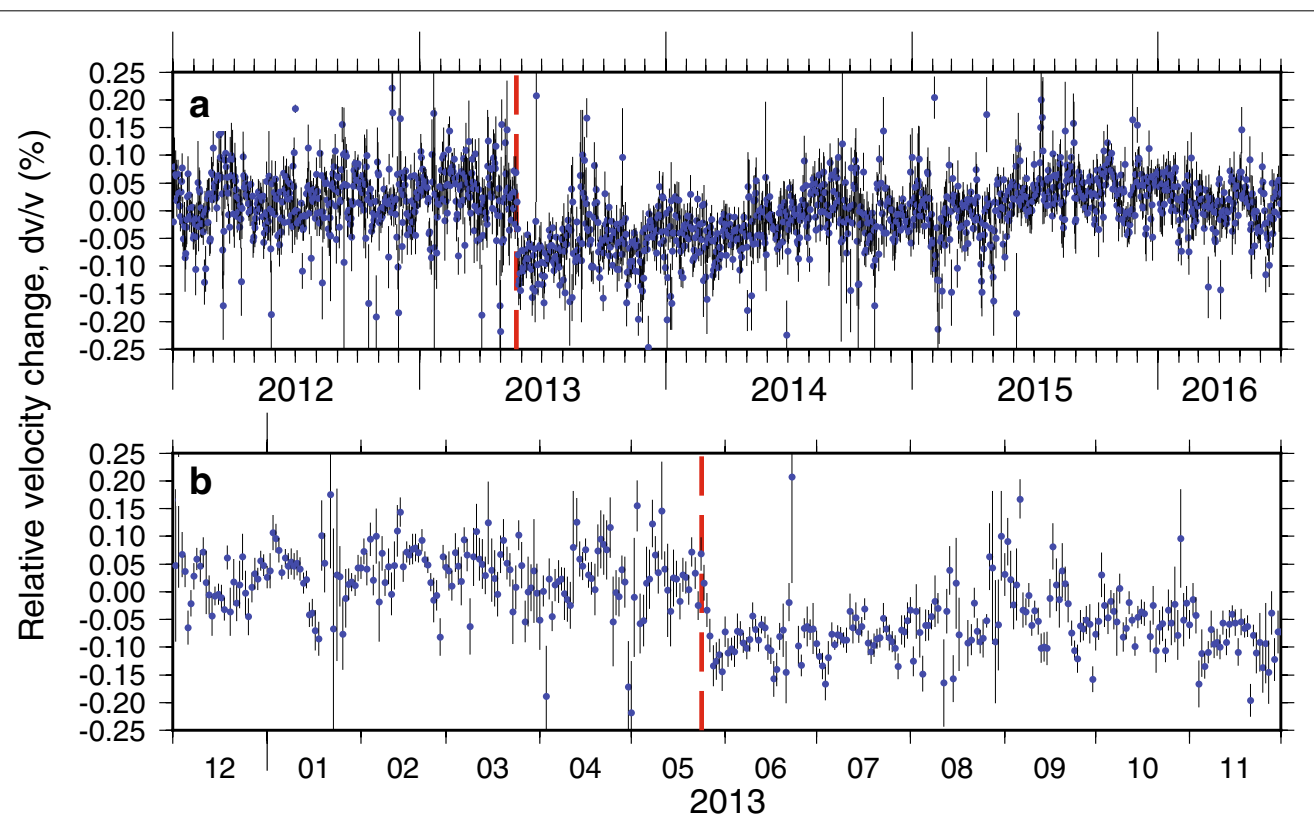

Fig. 3 Time history of relative velocity change $d v / v$ for stack of 5 days in a frequency range of $0.1-0.9 \mathrm{~Hz}$ from the coda window ranging from -50 to $-20 \mathrm{~s}$ and 20 to $50 \mathrm{~s}$, with two sigma standard deviations in the time intervals a January 2012 through June 2016 and b December 2012 through November 2013. Note that the $\mathrm{d} v / v$ was plotted at the end of the time window for stacking NCFs. Dashed red line is the occurrence time of the 24 May 2013 M 5.7 Greenville earthquake 


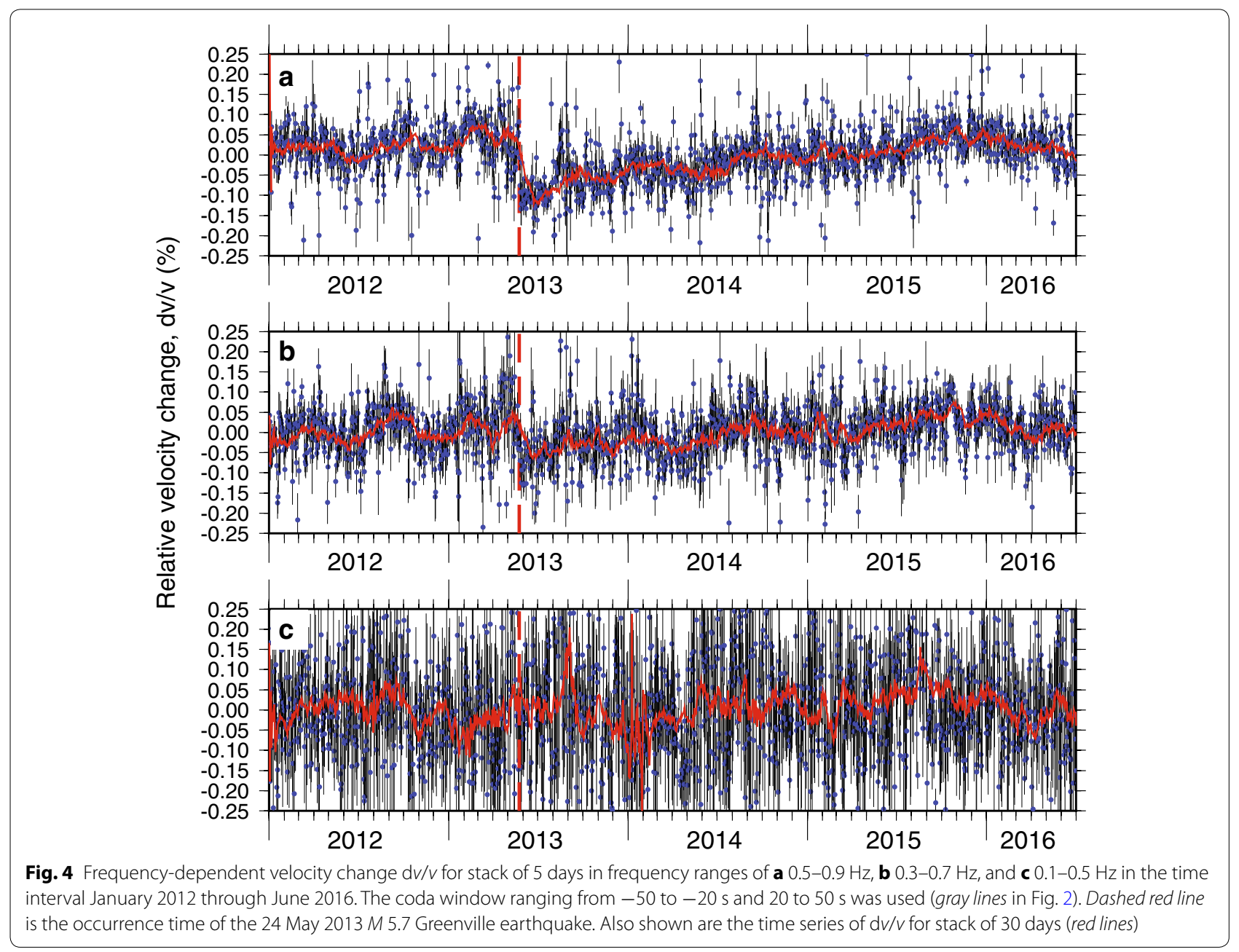

The frequency-dependent variability in $\mathrm{d} v / v$ observed can constrain the depths of the velocity changes through the sensitivity kernel of surface waves. We derived a onedimensional S-wave velocity (Vs) model from the onedimensional P-wave velocity (Vp) model (Fig. 6b) that is used to locate LVC local earthquakes by USGS, assuming the $V \mathrm{p} / V \mathrm{~s}$ ratio of 1.76 (F. Klein personal communication). With the Computer Programs in Seismology package (Herrmann 2013), we evaluated the sensitivity kernel (Fig. 6a) with the USGS one-dimensional velocity model. Note that the depths described are measured from surface throughout this study. We use the Rayleigh-wave sensitivity kernel to evaluate the depth extents of velocity changes. As shown in Fig. 2, our analysis was limited to use ZZ, ZR, ZT, RZ, and TZ components in NCFs. In those components, Rayleigh wave would be more dominant than Love wave.

Love wave would be most clearly observed in the TT component that we were not able to obtain from our dataset. It should be noted, however, that we analyzed the coda of NCFs in which the scattered Love waves would be included. Our estimation of the depth extents in velocity changes is therefore biased if Love waves are dominant in the coda of NCFs analyzed. However, this bias would be primarily profound when two horizontal components are used for noise cross-correlation analysis (i.e., TR component). There is no NCF obtained by cross-correlating two horizontal components in our dataset. A complex anisotropic structure and topography would introduce contaminations of Love waves in the ZZ, ZR, ZT, RZ, and $\mathrm{TZ}$ components we analyzed. However, it is very unlikely that Love waves are more dominant than Rayleigh waves in those five NCF components due to effects from anisotropic structure and topography.

With the Rayleigh-wave sensitivity kernel, the surface waves in the frequency range of $0.1-0.9 \mathrm{~Hz}$ propagate at least down to $10 \mathrm{~km}$ depth and cover the whole LVC seismogenic zone (Fig. 6b). Note, however, that the majority of low-frequency earthquakes that are likely related to the movement of magmatic fluid occurred at 


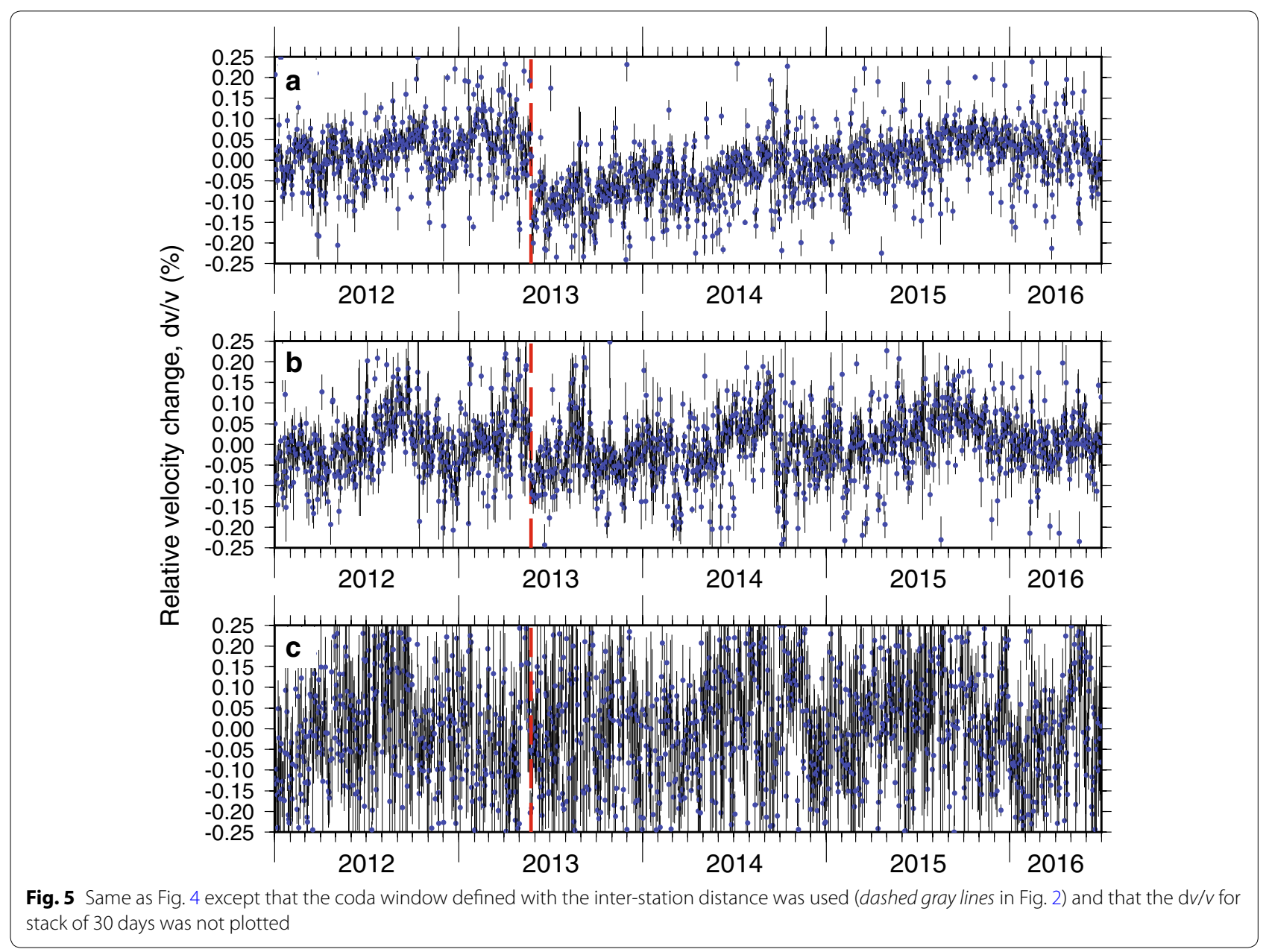

a depth of 15-20 km (Pitt et al. 2002). With this sensitivity kernel, the 2013 velocity reduction registered only in the $0.5-$ to $0.9-\mathrm{Hz}$ band most likely occurred at depth of $\sim 1 \mathrm{~km}$.

\section{Discussion}

As shown in Figs. 4a and 5a, we observe a sudden velocity reduction of about $0.1 \%$ occurring in late May 2013. The onset time of this velocity reduction suggests that the velocity reduction is likely associated with the $M$ 5.7 Greenville earthquake (Fig. 7a). We hypothesize that the velocity reduction is associated with opening of cracks in the hydrothermal system of the LVC due to stress changes triggered by the Greenville earthquake. Our frequency-dependent $\mathrm{d} v / v$ observation also suggests that the velocity change occurred at $\sim 1 \mathrm{~km}$ depth range (Fig. 6a). Note, however, that our dataset was not sensitive to velocity changes in the first $1 \mathrm{~km}$ depth because the upper bound of the frequency range is $0.9 \mathrm{~Hz}$ (Fig. 6a), although there is a slight increase of the sensitivity at the superficial layer.
A range of static stress changes was computed with a circular crack model (Aki and Richards 1980). Assuming a stress drop of 1-10 MPa with a rupture length of 5-10 km for the $M 5.7$ Greenville earthquake, the static stress change at the LVC would be an order of 0.0001$0.001 \mathrm{MPa}$. On the other hand, the dynamic stress change is estimated to be $0.17 \mathrm{MPa}$ based on the peak ground velocity observation at station $\mathrm{LDH}\left(1.3 \mathrm{cms}^{-1}\right)$, assuming the shear-wave velocity of $2.3 \mathrm{kms}^{-1}$ and the shear modulus of $30 \mathrm{GPa}$. The dynamic stress change would be two orders of magnitude higher than the static stress changes. With these stress change estimates, we suggest that the dynamic stress is responsible for the 2013 velocity reduction. We also searched for an increase of LVC seismicity that is remotely triggered by the Greenville mainshock and find that there is no elevated seismicity (Fig. 7a).

The observed velocity reduction allows us to estimate the seismic velocity susceptibility that is defined as the ratio of the change in velocity and the dynamic stress (Brenguier et al. 2014). Chaves and Schwartz 


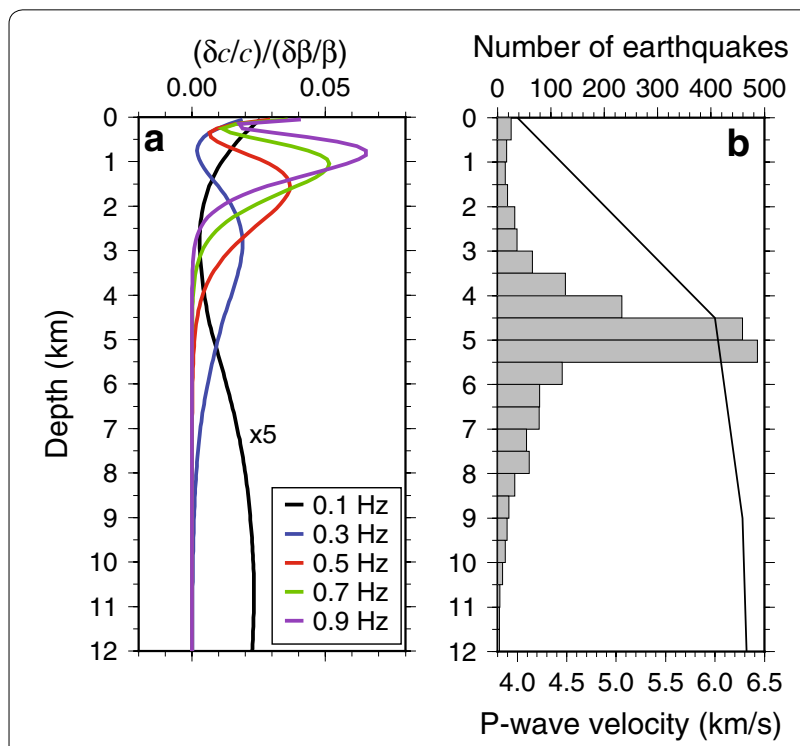

Fig. 6 a Frequency-dependent Rayleigh surface-wave sensitivity to velocity perturbations that constitute a proxy for depth resolution. The sensitivity kernel for the $0.1-\mathrm{Hz}$ band (black line) is exaggerated by a factor of 5. $\mathbf{b}$ The depth distribution of earthquakes during January 1984 through June 2016 shown in Fig. 1. Also shown is the one-dimensional P-wave velocity model (black line) used by USGS to locate the LVC local earthquakes. A one-dimensional S-wave velocity model was derived from this P-wave velocity model with the Vp/Vs ratio of 1.76

(2016) identified an overpressurized layer within the subduction zone in northern Costa Rica through the estimate in seismic velocity susceptibility. With the dynamic stress of $0.17 \mathrm{MPa}$ and velocity reduction of $0.1 \%$, the velocity susceptibility is estimated to be about $0.006 \mathrm{MPa}^{-1}$. This resultant velocity susceptibility of $0.006 \mathrm{MPa}^{-1}$ is lower than those summarized in Yamamura et al. (2003) except for the Sano et al. (1999) field experiment $\left(0.005 \mathrm{MPa}^{-1}\right)$. It should be noted, however, that these estimations of velocity susceptibility are associated with velocity changes in shallow layer (the top $10-450 \mathrm{~m}$ depth) where the velocity susceptibility is expected to be high because of low confining pressure. Generally, the seismic velocity susceptibility will be decreased with increasing of depth due to an increase of the confining pressure. In fact, the lowest velocity susceptibility $\left(0.005 \mathrm{MPa}^{-1}\right)$ listed in Yamamura et al. (2003) was obtained from the velocity change observed at a depth of $450 \mathrm{~m}$ inside the Kamaishi mine tunnel, Japan (Sano et al. 1999).

On the contrary, our analysis made use of seismic data in a frequency of $0.1-0.9 \mathrm{~Hz}$, suggesting that a depth of the velocity change related to the 2013 Greenville earthquake is about $1 \mathrm{~km}$ depth from the Rayleigh-wave sensitivity kernel shown in Fig. 6a. At this depth, a value of velocity susceptibility would be lower than those summarized in Yamamura et al. (2003) due to a higher confining pressure. To get insight into the nature of the velocity susceptibility of $0.006 \mathrm{MPa}^{-1}$ obtained at the LVC, we compared it with the velocity susceptibility measurements from Brenguier et al. (2014) that analyzed ambient noise seismic data in the same frequency band $(0.1-0.9 \mathrm{~Hz})$ used in our analysis. We assume that both studies extract the values of velocity susceptibility at similar depth. With this assumption, the confining pressure would be in the same range.

Brenguier et al. (2014) identifies the zones of high velocity susceptibility $\left(>0.0005 \mathrm{MPa}^{-1}\right)$ that are spatially correlated with hydrothermal and volcanic fields. They suggest that an effective confining pressure will be reduced due to highly pressurized hydrothermal and magmatic fluid, proposing that a reduction of the confining pressure will be responsible for the high values of velocity susceptibility. We find that this velocity susceptibility obtained at the LVC is higher than or comparable to those obtained in Mt Fuji and other hydrothermal areas in Japan by Brenguier et al. (2014), which would indicate that there would be an existence of high-pressurized hydrothermal fluid at the LVC.

Geochemical studies suggest that the Lassen hydrothermal system consisted of a large vapor-dominated zone that contains mixtures of the heated water and dissolved volcanic gases in the upper 1-2 km depth (Clynne et al. 2003). A highly pressurized hydrothermal fluid in the vapor-dominated zone might be responsible for the resultant velocity susceptibility of $0.006 \mathrm{MPa}^{-1}$ obtained. We speculate that the dynamic stress from the Greenville earthquake induces steam-heated water from the vapordominated zone to prevail in open fractures at the nearsurface layer.

Another possible mechanism of a sudden velocity reduction in surface layer is heavy precipitation (e.g., Sens-Schönfelder and Wegler 2006; Meier et al. 2010; Hillers et al. 2014; Rivet et al. 2015). We examined the continuous hydrological dataset at LVC maintained by National Oceanic and Atmospheric Administration (NOAA). They are, however, "modeled" hydrology products. Although it is less clear about the physical model and parameters behind this NOAA's modeling, it appears that this is the best dataset to address a long-term LVC precipitation. We extracted precipitation data modeled at Lassen Peak (site code LLPC1; about $1 \mathrm{~km}$ east from station LEL) from NOAA (http://www.nohrsc.noaa. gov/interactive/html/graph.html?station $=\mathrm{LLPC1}$; last accessed on September 8, 2016). From the NOAA dataset, no heavy precipitation was identified, although there were light precipitations before and after the occurrence time of the Greenville earthquake (Fig. 7a). 

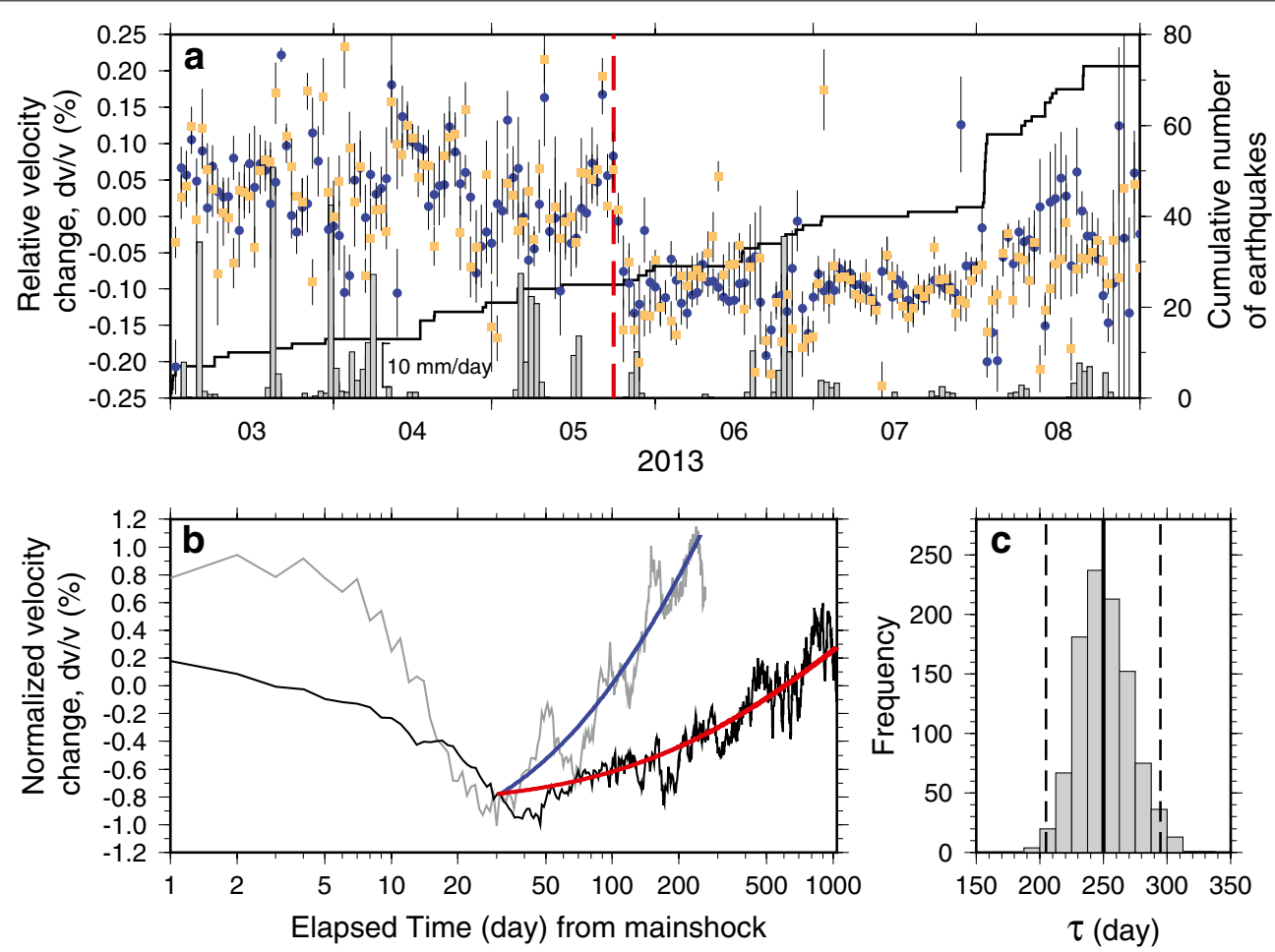

Fig. 7 a Coseismic velocity reduction associated with the 24 May 2013 M 5.7 Greenville earthquake (dashed red line). Blue circles and orange squares are $\mathrm{d} v / \mathrm{v}$ for stack of 5 days in a frequency range of $0.5-0.9 \mathrm{~Hz}$ from two different coda windows: (1) -50 to $-20 \mathrm{~s}$ and 20 to $50 \mathrm{~s}$ and (2) the interstation distance dependent, respectively. Black line represents the cumulative number of earthquakes that occurred within $10 \mathrm{~km}$ from station LEL from March 1, 2013. Also shown in the modeled precipitation (gray bars) at Lassen Peak. b The postseismic velocity recovery following the 2013 Greenville earthquake. Black line is $\mathrm{d} v / \mathrm{v}$ for stack of 30 days in a frequency range of $0.1-0.9 \mathrm{~Hz}$ with the coda window ranging from -50 to $-20 \mathrm{~s}$ and 20 to $50 \mathrm{~s}$. Red line is a synthetic velocity change modeled by a logarithmic velocity recovery with the median model parameters. Note that the velocity changes were normalized by the maximum velocity drop. Also shown is the seismic velocity change (gray line) at the San Andreas fault, induced by the 2003 M 6.6 San Simeon earthquake (Brenguier et al. 2008a) and its synthetic velocity change (blue line). Note that we only show Brenguier's result in the first 285-day postseismic period to avoid another velocity reduction due to the 2004 M 6.0 Parkfield earthquake. c Distribution of the relaxation time $(\tau)$ from the bootstrap analysis with 1000 subsample datasets. The black line indicates the median value (250 days), and dashed lines are the 95th confidence interval (213-294 days)

Following the velocity reduction, $\mathrm{d} v / v$ appears to remain at $\sim 0.1 \%$ in the first $3-4$ months and then gradually increased. The postseismic velocity recovery could be modeled as a logarithmic function (Vidale and Li 2003) with $\mathrm{d} v / v(t)=\gamma \log _{e}(1+t / \tau)$ where $\tau$ is a characteristic relaxation time and $t$ is the elapsed time following the Greenville mainshock; $\gamma$ is a constant to be estimated. To characterize the relaxation time observed at the LVC, we compare the velocity recovery at the LVC with another velocity change at the San Andreas fault, California, induced by the $2003 M$ 6.6 San Simeon earthquake (Brenguier et al. 2008a). To remove any bias from data processing for the comparison of $\tau$, we used the same frequency band and the length of the time window for stacking NCFs that were used in Brenguier et al. (2008a). We inverted the time history of $\mathrm{d} v / v$ for stack of 30 days in a frequency of $0.1-0.9 \mathrm{~Hz}$ to determine $\tau$ (and $\gamma$ ) for both the Greenville and San Simeon velocity recovery processes through a least-squares method (Fig. 7b).

We employed a bootstrap approach to obtain the 95th confidence intervals of model parameters (Efron and Tibshirani 1993) where a subsampled dataset was obtained by randomly sampling $\mathrm{d} v / v$ data point from the entire $\mathrm{d} v / v$ time series. The total data point of the subsampled dataset is the same as that of the original $\mathrm{d} v / v$ time series. We obtained 1000 individual subsampled datasets with this resampling process and performed a least-squares fitting of each subsampled dataset to determine the distribution of $\tau$ (and $\gamma$ ) (Fig. 7c). With these 1000 subsampled datasets, $\tau$ is found to be ranged from 213 to 294 days with a median value of 250 days (Fig. 7c). The resultant $\tau$ for the postseismic velocity recovery for the $2003 \mathrm{San}$ Simeon (shown in Fig. 7b) is obtained to be 136 days and its 95th confidence interval is 102-187 days. The LVC 
median relaxation time is about 100 days longer than that obtained at the San Andreas fault, which would suggest that the cracks produced by the Greenville earthquake were slowly closed. A large volume of steam-heated water surrounding the cracks might sustain opening of cracks over several months, leading to a notable slow recovery process.

Our $\mathrm{d} v / v$ measurements also reveal long-term variations of seismic velocity in the lower frequency bands $(0.3-0.7 \mathrm{~Hz}$ and $0.1-0.5 \mathrm{~Hz})$. A seasonal variation in the 0.1 - to $0.5-\mathrm{Hz}$ band shown in Figs. $4 \mathrm{c}$ and $5 \mathrm{c}$ might be primarily due to time-dependent noise source distribution (e.g., Hadziioannou et al. 2011; Zhan et al. 2013; Hillers et al. 2015). Additionally, the uncertainties in the majority of $\mathrm{d} v / v$ measurements on a 5 -day stack exceed $0.1 \%$, which could introduce bias into the estimate of the longterm velocity change. We thus only explore the underlying mechanism of the long-term velocity variation in the $0.3-$ to $0.7-\mathrm{Hz}$ band in which a recurrent reduction of velocity was observed during the winter season (Figs. $4 \mathrm{~b}, 5 \mathrm{~b}$ ). It should be noted that $\mathrm{d} v / v$ also decreases in the summer season in 2012 and 2013. A part of the 2013 summer velocity reduction might be a response to the dynamic stress change from the Greenville earthquake. A weak long-term trend might be observed in the $0.5-$ to $0.9-\mathrm{Hz}$ band (Figs. $4 \mathrm{a}, 5 \mathrm{a}$ ), although this longterm trend is superimposed into the coseismic and postseismic velocity changes associated with the Greenville earthquake. Based on the surface-wave sensitivity kernel (Fig. 6a), our observation suggests that the long-term velocity change occurred in a depth of $2-4 \mathrm{~km}$ range rather than in the near-surface layer.

Christiansen et al. (2005) explored seasonal variations in seismicity at several volcanic centers in the western USA including the LVC and find no clear seasonal seismicity at the LVC from an earthquake catalog for two decades (1984-2004). It should be noted, however, that their time interval does not overlap with our analysis period. In contrast to the seismicity analysis, continuous geodetic measurements have revealed seasonal deformation and long-term subsidence in and around the LVC. Recent studies document that the LVC has been subsiding since at least the 1990s (Poland et al. 2004; Parker et al. 2016). A number of models for the subsidence have been proposed, including crustal extension and cooling magma. However, the physical mechanism of the longterm Lassen subsidence still remains unclear. In addition to this long-term subsidence, the LVC experiences seasonal vertical deformation. The snow depth modeled by NOAA at Lassen Peak seems to be anti-correlated with the vertical deformation (Fig. 8), which suggests that the observed vertical deformation is most likely due to regional hydrological (snow and rain) loading (Amos et al. 2014; Borsa et al. 2014). During the winter seasons, an increase of surface loading causes downward motion. Continuously operating Global Positioning System (GPS) operated by the Plate Boundary Observatory shows that the amplitude of seasonal vertical motion is about $\pm 10 \mathrm{~mm}$.

An increase of surface loading from rain and snow may trigger pore fluid diffusion that increases pressure in fluid-filled cracks and consequently reduces seismic velocity (Mordret et al. 2016). However, the same loading effect will also increase confining pressure at depth that can lead to an increase of seismic velocity by closing cracks (Hotovec-Ellis et al. 2014). Silver et al. (2007) find both increase and decrease of velocity changes during an increase of atmospheric pressure loading from active source experiments. They find that an increase of atmospheric pressure causes reductions of velocity nearby water wells whereas increases in velocity far from wells, proposing that the polarity of velocity change (i.e., positive or negative velocity change) due to surface loading will be controlled by whether or not a large volume of fluid exists nearby fracture zones. Following Silver et al. (2007), the presence of a large active hydrothermal system at the LVC will lead to a velocity reduction with an increase of surface loading, which is consistent with our observation shown in Fig. 8 a.

Another source of seasonal velocity variation may be thermoelastic strain changes (Hillers et al. 2015). Tsai (2011) considered thermoelastic, poroelastic, and elastic hydrological load models to explain the coherence of seasonal variation between vertical deformation and seismic velocity change. The thermoelastic model predicts that velocity changes decrease exponentially as a function of depth. This depth dependency from thermoelastic model is inconsistent with our observation. Another observational constraint is a phase delay between the geodetic deformation and velocity change. The elastic load model requires an instantaneous velocity change, whereas the poroelastic load model leads to a seismic velocity lags behind a change in vertical deformation.

We performed a moving-window coherence analysis between the ground deformation and velocity change with a 1-year time window with $20 \%$ overlap to identify the phase lag and coherence (Fig. 8b). This 1-year time window was selected to stabilize the coherence analysis. We used the $\mathrm{d} v / v$ time series for stack of 30 days in the frequency range of $0.3-0.7 \mathrm{~Hz}$ (the red line in Fig. $8 \mathrm{a}$ ) and a 30-day running median vertical displacement collected at P668 GPS site (the green line in Fig. 8a). This GPS site has been in operational with minimal data gaps in and around the LVC. Note, however, that the data after January 2016 were not available. The phase lag and coherence were determined through a liner fit of the cross-spectrum 


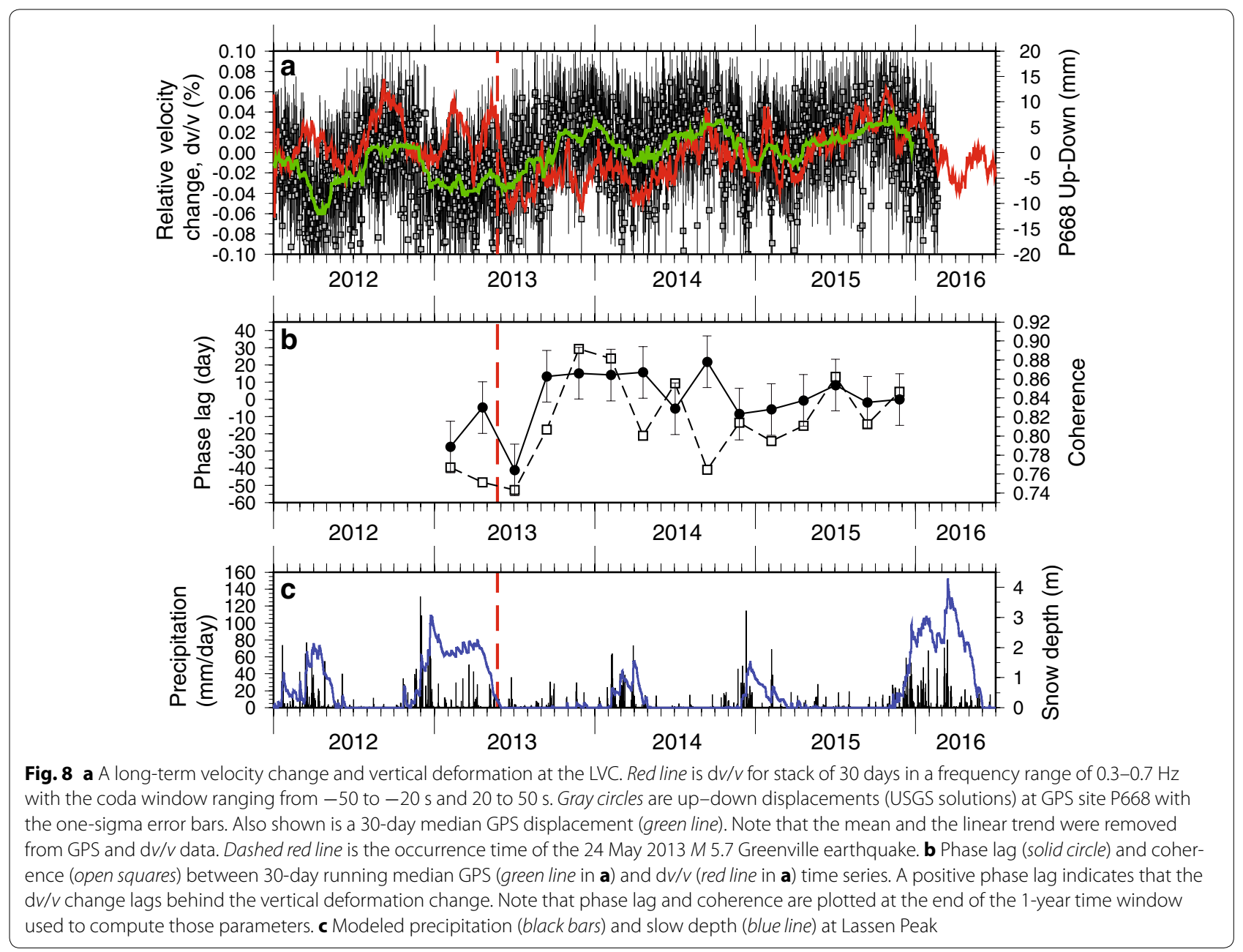

between the $\mathrm{d} v / v$ and GPS data in a frequency domain. The linear fit was performed in the period above 30 days because the $\mathrm{d} v / v$ and GPS data were already smoothed by a 30-day time window. The uncertainty of the phase lag was computed based on the residual of the linear fit to the cross-spectrum. We set the lower limit of the uncertainty to be \pm 15 days because of a 30 -day time widow applied to the $\mathrm{d} v / v$ and GPS data.

We find that the coherence exceeds 0.7 for the entire time period analyzed. The phase lag was varied over time, especially the time interval around the 2013 Grenville earthquake. However, we find that the phase lag is stable at close to 0 day during 2014-2015. This observation can be interpreted that the velocity changes at least in the last $\sim 2$ years are mostly controlled by either elastic loading or poroelastic response with notable high fracture permeability. It should be noted, however, that the seismic velocity was not correlated with vertical deformation in January-June in 2013, which indicates that there might be other underlying process of the long-term velocity variation. Groundwater measurement is a key observation to access the hydrological load model in the seismogenic crust (Sens-Schönfelder and Wegler 2006; Hillers et al. 2015; Rivet et al. 2015). However, continuous hydrological (groundwater and precipitation) data were not available at the LVC. Also, snowmelt will significantly increase in groundwater level (Saar and Manga 2003), which should be taken into account for modeling. Due to a lack of direct hydrological observations, we were not able to model velocity changes with hydrological load models.

The amplitude of velocity changes from the hydrological load models (elastic and poroelastic) is mainly controlled by porosity and hydraulic diffusivity (Tsai 2011). Both porosity and hydraulic diffusivity will be proportional to fracture permeability (Zoback 2007). A highpermeable layer will lead to a large variation in seismic velocity. Our $\mathrm{d} v / v$ measurement therefore suggests a 
high-permeable layer at a depth of 2-4 km. It appears that the background LVC seismicity also suggests a high level of porosity in this depth range. As shown in Fig. 6b, the background LVC seismicity is concentrated at 3-6 km depth. A layer of thermal cracking with heatedhydrothermal fluid has been suggested to be responsible for clusters of the Lassen seismicity in this depth range (Janik and McLaren 2010), which in turn lead to a high-permeability zone and also reflect a volume of high porosity and high hydraulic diffusivity. In addition to the LVC seismicity, clusters of earthquake activity at volcanic areas are likely driven by hydrothermal fluid migration through highly permeable pathways (Waite 2002; Shelly et al. 2013, 2015). Our working hypothesis is that the thermal cracking layer is very sensitive to changes in surface loading and that an increased surface loading instantaneously induces hydrothermal fluid pressure diffusion serving to open cracks and reduce seismic velocity.

\section{Conclusions}

A quasi real-time monitoring system for seismic velocity at the LVC is established by making use of seismic interferometry approach with the continuous data archived at NCEDC. We document responses of the Lassen hydrothermal system to external stressing through time evolution of seismic velocity. Our monitoring system identifies a sudden velocity reduction of $\sim 0.1 \%$ in a depth of $1 \mathrm{~km}$. This velocity reduction is most likely due to opening of cracks at $1 \mathrm{~km}$ depth created by the dynamic stress change from the 24 May 2013 M 5.7 Greenville earthquake. The seismic velocity susceptibility as a ratio of the velocity change to the dynamic stress change is about $0.006 \mathrm{MPa}^{-1}$, which suggests that the Lassen hydrothermal system is characterized by notably pressurized hydrothermal fluid. Our monitoring system also reveals a long-term velocity variation that is mostly correlated with hydrological-induced vertical deformation over time. Our observation suggests that an increase of surface loading induces a hydrothermal fluid pressure transient that leads to a reduction of seismic velocity by opening of cracks in a depth of $2-4 \mathrm{~km}$ at which it was suggested that there exists an active vapor-dominated zone. We hypothesize that the long-term variation in seismic velocity is primarily controlled by the hydrological model with either elastic or poroelastic loading and that represents changes in thermal crack density at the vapor-dominated zone.

\footnotetext{
Abbreviations

GPS: Global Positioning System; NCEDC: Northern California Earthquake Data Center; NCFs: noise cross-correlation functions; NCSS: Northern California Seismic Network; NOAA: National Oceanic and Atmospheric Administration; LVC: Lassen Volcanic Center; USGS: United States Geological Survey.
}

\section{Authors' contributions}

TT led and designed the whole research and drafted the manuscript, analyzed seismic data, generated the figures, and contributed to the examination of the results. FB contributed to the interpretation of the results. All authors discussed the results and commented on the manuscript. Both authors read and approved the final manuscript.

\section{Author details}

1 Berkeley Seismological Laboratory, University of California, Berkeley, CA 94720, USA. ${ }^{2}$ Institut des Sciences de la Terre, Université Grenoble Alpes, CNRS, Grenoble, France.

\section{Acknowledgements}

We would like to thank Christopher Johnson, Yan Hu, and Avinash Nayak for discussion about the geodetic measurements, postseismic deformation, and noise-correlation analysis. Roland Bürgmann and Michael Manga provided constructive reviews of an early draft of this manuscript. The constructive comments from two anonymous reviewers and the handling editor Takuto Maeda improved the manuscript significantly. We thank the Editor-in-Chief Yasuo Ogawa for inviting us to submit this manuscript. Waveform data, metadata, and earthquake catalog for this study were accessed through the Northern California Earthquake Data Center (NCEDC) (NCEDC 2014). The Berkeley Seismological Laboratory (BSL) and U.S. Geological Survey contributed these data to the NCEDC. A python software package, ObsPy (Beyreuther et al. 2010) was used to process seismic data. A software package, Generic Mapping Tools (GMT) (Wessel et al. 2013) was used for plotting figures. This study was supported by the France-Berkeley Fund 2014-0051 and the National Science Foundation EAR-1053211. This is BSL Contribution Number 2016-08.

\section{Competing interests}

The authors declare that they have no competing interests.

Received: 28 July 2016 Accepted: 24 September 2016

Published online: 06 October 2016

\section{References}

Aki K, Richards PG (1980) Quantitative seismology_theory and methods. W. H. Freeman, New York

Amos CB, Audet P, Hammond WC et al (2014) Uplift and seismicity driven by groundwater depletion in central California. Nature 509:483-486. doi:10.1038/nature13275

Beyreuther M, Barsch R, Krischer L et al (2010) ObsPy: a Python toolbox for seismology. Seismol Res Lett 81:530-533. doi:10.1785/gssrl.81.3.530

Borsa AA, Agnew DC, Cayan DR (2014) Ongoing drought-induced uplift in the western United States. Science 345:1587-1590. doi:10.1126/science.1260279

Brenguier F, Campillo M, Hadziioannou C et al (2008a) Postseismic relaxation along the San Andreas fault at Parkfield from continuous seismological observations. Science 321:1478-1481. doi:10.1126/science.1160943

Brenguier F, Shapiro NM, Campillo M et al (2008b) Towards forecasting volcanic eruptions using seismic noise. Nat Geosci 1:126-130. doi:10.1038/ ngeo 104

Brenguier F, Clarke D, Aoki Y et al (2011) Monitoring volcanoes using seismic noise correlations. Comptes Rendus Geosci 343:633-638. doi:10.1016/j. crte.2010.12.010

Brenguier F, Campillo M, Takeda T et al (2014) Mapping pressurized volcanic fluids from induced crustal seismic velocity drops. Science 345:80-82. doi:10.1126/science.1254073

Brenguier F, Rivet D, Obermann A et al (2016) 4-D noise-based seismology at volcanoes: ongoing efforts and perspectives. J Volcanol Geotherm Res 321:182-195. doi:10.1016/j.jvolgeores.2016.04.036

Caudron C, Lecoca T, Syahbana DK et al (2015) Stress and mass changes at a "wet" volcano: example during the 2011-2012 volcanic unrest at Kawah Ijen volcano (Indonesia). J Geophys Res Solid Earth 120:5117-5134. doi:1 $0.1002 / 2014 J B 011590$

Chaves EJ, Schwartz SY (2016) Monitoring transient changes within overpressured regions of subduction zones using ambient seismic noise. Sci Adv 2:e1501289. doi:10.1126/sciadv.1501289 
Christiansen LB, Hurwitz S, Saar MO et al (2005) Seasonal seismicity at western United States volcanic centers. Earth Planet Sci Lett 240:307-321. doi:10.1016/j.epsl.2005.09.012

Clarke D, Zaccarelli L, Shapiro NM, Brenguier F (2011) Assessment of resolution and accuracy of the moving window cross spectral technique for monitoring crustal temporal variations using ambient seismic noise. Geophys $J$ Int 186:867-882. doi:10.1111/j.1365-246X.2011.05074.x

Clynne MA, Muffler LJP (2010) Geologic Map of Lassen Volcanic National Park and Vicinity, California. US Geol Surv Sci Investig Rep Map 2899

Clynne MA, Janik CJ, Muffler LJP (2003) "Hot water" in Lassen Volcanic National Park-fumaroles, steaming ground, and boiling mudpots. US Geol Surv Fact Sheet 101-02

Clynne MA, Robinson JE, Nathenson M, Muffler LJP (2012) Volcano hazards assessment for the Lassen region, Northern California. US Geol Surv Sci Investig Rep 2012-5176-A

Efron B, Tibshirani RJ (1993) An introduction to the bootstrap. Champan and Hall, New York

Ewert J, Guffanti M, Cervelli P, Quick J (2006) The National Volcano Early Warning System (NVEWS). US Geol Surv Fact Sheet 2006-3142

Hadziioannou C, Larose E, Baig A et al (2011) Improving temporal resolution in ambient noise monitoring of seismic wave speed. J Geophys Res 116:B07304. doi:10.1029/2011JB008200

Haney MM, van Wijk K, Preston LA, Aldridge DF (2009) Observation and modeling of source effects in coda wave interferometry at Pavlof volcano. Lead Edge 28:554-560. doi:10.1190/1.3124930

Herrmann RB (2013) Computer programs in seismology: an evolving tool for instruction and research. Seismol Res Lett 84:1081-1088. doi:10.1785/0220110096

Hillers G, Campillo M, Ma KF (2014) Seismic velocity variations at TCDP are controlled by MJO driven precipitation pattern and high fluid discharge properties. Earth Planet Sci Lett 391:121-127. doi:10.1016/j. epsl.2014.01.040

Hillers G, Ben-Zion Y, Campillo M, Zigone D (2015) Seasonal variations of seismic velocities in the San Jacinto fault area observed with ambient seismic noise. Geophys J Int 202:920-932. doi:10.1093/gji/ggv151

Hotovec-Ellis AJ, Gomberg J, Vidale JE, Creager KC (2014) A continuous record of intereruption velocity change at Mount St. Helens from coda wave interferometry. J Geophys Res Solid Earth 119:2199-2214. doi:10.1002/2 014JB011151

Ingebritsen SE, Sorey M (1985) A quantitative analysis of the Lassen hydrothermal system, North Central California. Water Resour Res 21:853-868

Ingebritsen SE, Shelly DR, Hsieh PA et al (2015) Hydrothermal response to a volcano-tectonic earthquake swarm, Lassen, California. Geophys Res Lett. doi:10.1002/2015GL065826

Ingebritsen SE, Bergfeld D, Clor LE, Evans WC (2016) The Lassen hydrothermal system. Am Mineral 101:343-354. doi:10.2138/am-2016-5456

Janik CJ, McLaren MK (2010) Seismicity and fluid geochemistry at Lassen Volcanic National Park, California: evidence for two circulation cells in the hydrothermal system. J Volcanol Geotherm Res 189:257-277. doi:10.1016/j.jvolgeores.2009.11.014

Jaxybulatov K, Shapiro NM, Koulakov I et al (2014) A large magmatic sill complex beneath the Toba caldera. Science 346:617-619. doi:10.1126/ science. 1258582

Klein FW (1979) Earthquakes in Lassen Volcanic National Park, California. Bull Seismol Soc Am 69:867-875

Lecocq T, Caudron C, Brenguier F (2014) MSNoise, a Python package for monitoring seismic velocity changes using ambient seismic noise. Seismol Res Lett 85:715-726. doi:10.1785/0220130073

Meier U, Shapiro NM, Brenguier F (2010) Detecting seasonal variations in seismic velocities within Los Angeles basin from correlations of ambient seismic noise. Geophys J Int. doi:10.1111/j.1365-246X.2010.04550.x

Moran SC (2004) Seismic monitoring at Cascade Volcanic Centers, 2004-status and recommendations. US Geol Surv Sci Investig Rep 2004-5211:22 p

Mordret A, Mikesell TD, Harig C et al (2016) Monitoring southwest Greenland's ice sheet melt with ambient seismic noise. Sci Adv 2:E1501538

Muffler LJP, Nehring NL, Truesdell AH, et al. (1982) The Lassen geothermal system. Proc Fourth New Zeal Geotherm Work Auckland, New Zeal 349-356

Nagaoka Y, Nishida K, Aoki Y, Takeo M (2010) Temporal change of phase velocity beneath Mt. Asama, Japan, inferred from coda wave interferometry. Geophys Res Lett 37:L22311. doi:10.1029/2010GL045289
NCEDC (2014) Northern California Earthquake Data Center. UC Berkeley Seismological Laboratory. Dataset. doi:10.7932/NCEDC

Norris RD, Meagher KL, Weaver CS (1997) The 1936, 1945-1947, and 1950 earthquake sequences near Lassen Peak, California. J Geophys Res Solid Earth 102:449-457

Obermann A, Planès T, Larose E et al (2013a) Depth sensitivity of seismic coda waves to velocity perturbations in an elastic heterogeneous medium. Geophys J Int 194:372-382. doi:10.1093/gji/ggt043

Obermann A, Planès T, Larose E, Campillo M (2013b) Imaging preeruptive and coeruptive structural and mechanical changes of a volcano with ambient seismic noise. J Geophys Res 118:6285-6294. doi:10.1002/2013JB010399

Parker AL, Biggs J, Lu Z (2016) Time-scale and mechanism of subsidence at Lassen Volcanic Center, CA, from InSAR. J Volcanol Geotherm Res 320:117-127. doi:10.1016/j.jvolgeores.2016.04.013

Pitt AM, Hill DP, Walter SW, Johnson MJS (2002) Midcrustal, long-period earthquakes beneath Northern California volcanic areas. Seismol Res Lett 73:144-152. doi:10.1785/gssrl.73.2.144

Poland M, Bawden G, Lisowski M, Dzurisin D (2004) Newly discovered subsidence at Lassen Peak, southern Cascade Range, California, from InSAR and GPS. Am Geophys, Union Fall Meet

Rivet D, Brenguier F, Cappa F (2015) Improved detection of preeruptive seismic velocity drops at the Piton de la Fournaise volcano. Geophys Res Lett 42:6332-6339. doi:10.1002/2015GL064835

Saar MO, Manga M (2003) Seismicity induced by seasonal groundwater recharge at Mt. Hood, Oregon. Earth Planet Sci Lett 214:605-618. doi:10.1016/S0012-821X(03)00418-7

Sano O, Hieda K, Hirano K, et al. (1999) Stress-sensitivity of the sound velocity at Kamaishi mine. In: Seismol Soc Japan 1999 Fall Meet

Sens-Schönfelder C (2008) Synchronizing seismic networks with ambient noise. Geophys J Int 174:966-970. doi:10.1111/j.1365-246X.2008.03842.x

Sens-Schönfelder C, Wegler U (2006) Passive image interferometry and seasonal variations of seismic velocities at Merapi Volcano, Indonesia. Geophys Res Lett 33:L21302. doi:10.1029/2006GL027797

Shelly DR, Hill DP, Massin F et al (2013) A fluid-driven earthquake swarm on the margin of the Yellowstone caldera. J Geophys Res Solid Earth 118:48724886. doi:10.1002/jgrb.50362

Shelly DR, Taira T, Prejean SG et al (2015) Fluid-faulting interactions: fracturemesh and fault-valve behavior in the February 2014 Mammoth Mountain, California earthquake swarm. Geophys Res Lett 42:5803-5812. doi:10.100 2/2015GL064325

Silver PG, Daley TM, Niu F, Majer EL (2007) Active source monitoring of crosswell seismic travel time for stress-induced changes. Bull Seismol Soc Am 97:281-293. doi:10.1785/0120060120

Spica Z, Legrand D, Iglesias A et al (2015) Hydrothermal and magmatic reservoirs at Lazufre volcanic area, revealed by a high-resolution seismic noise tomography. Earth Planet Sci Lett 421:27-38. doi:10.1016/j. epsl.2015.03.042

Stehly L, Campillo M, Shapiro NM (2007) Traveltime measurements from noise correlation: stability and detection of instrumental time-shifts. Geophys J Int 171:223-230. doi:10.1111/j.1365-246X.2007.03492.x

Stehly L, Campillo M, Froment B, Weaver RL (2008) Reconstructing Green's function by correlation of the coda of the correlation (C3) of ambient seismic noise. J Geophys Res Solid Earth 113:B11306. doi:10.1029/200 8JB005693

Taira T, Brenguier F, Kong Q (2015) Ambient noise-based monitoring of seismic velocity changes associated with the $2014 M_{w} 6.0$ South Napa earthquake. Geophys Res Lett 42:6997-7004. doi:10.1002/2015GL065308

Tsai VC (2011) A model for seasonal changes in GPS positions and seismic wave speeds due to thermoelastic and hydrologic variations. J Geophys Res Solid Earth 116:B04404. doi:10.1029/2010JB008156

Vidale JE, LiY (2003) Damage to the shallow Landers fault from the nearby Hector Mine earthquake. Nature 421:524-526. doi:10.1038/nature01354

Waite GP (2002) Seismic evidence for fluid migration accompanying subsidence of the Yellowstone caldera. J Geophys Res 107:2177. doi:10.1029/2 $001 \mathrm{JB} 000586$

Waldhauser F (2009) Near-real-time double-difference event location using long-term seismic archives, with application to northern California. Bull Seismol Soc Am 99:2736-2748. doi:10.1785/0120080294

Waldhauser F, Schaff DP (2008) Large-scale relocation of two decades of Northern California seismicity using cross-correlation and double-difference methods. J Geophys Res 113:B08311. doi:10.1029/2007JB005479 
Wegler U, Nakahara H, Sens-Schönfelder C et al (2009) Sudden drop of seismic velocity after the $2004 M_{w} 6.6$ mid-Niigata earthquake, Japan, observed with passive image interferometry. J Geophys Res 114:B06305. doi:10.10 29/2008JB005869

Wessel P, Smith WHF, Scharroo R et al (2013) Generic mapping tools: improved version released. Eos Trans Am Geophys Union 94:409-410. doi:10.1002/ 2013EO450001

Wu C, Delorey A, Brenguier F et al (2016) Constraining depth range of S wave velocity decrease after large earthquakes near Parkfield. Geophys Res Lett, California. doi:10.1002/2016GL069145
Yamamura K, Sano O, Utada H et al (2003) Long-term observation of in situ seismic velocity and attenuation. J Geophys Res 108:2317. doi:10.1029/2 002JB002005

Zhan Z, Tsai VC, Clayton RW (2013) Spurious velocity changes caused by temporal variations in ambient noise frequency content. Geophys J Int 194:1574-1581. doi:10.1093/gji/ggt170

Zoback MD (2007) Reservoir geomechanics. Cambridge University Press, Cambridge

\section{Submit your manuscript to a SpringerOpen ${ }^{\circ}$ journal and benefit from:}

- Convenient online submission

- Rigorous peer review

- Immediate publication on acceptance

- Open access: articles freely available online

- High visibility within the field

- Retaining the copyright to your article 